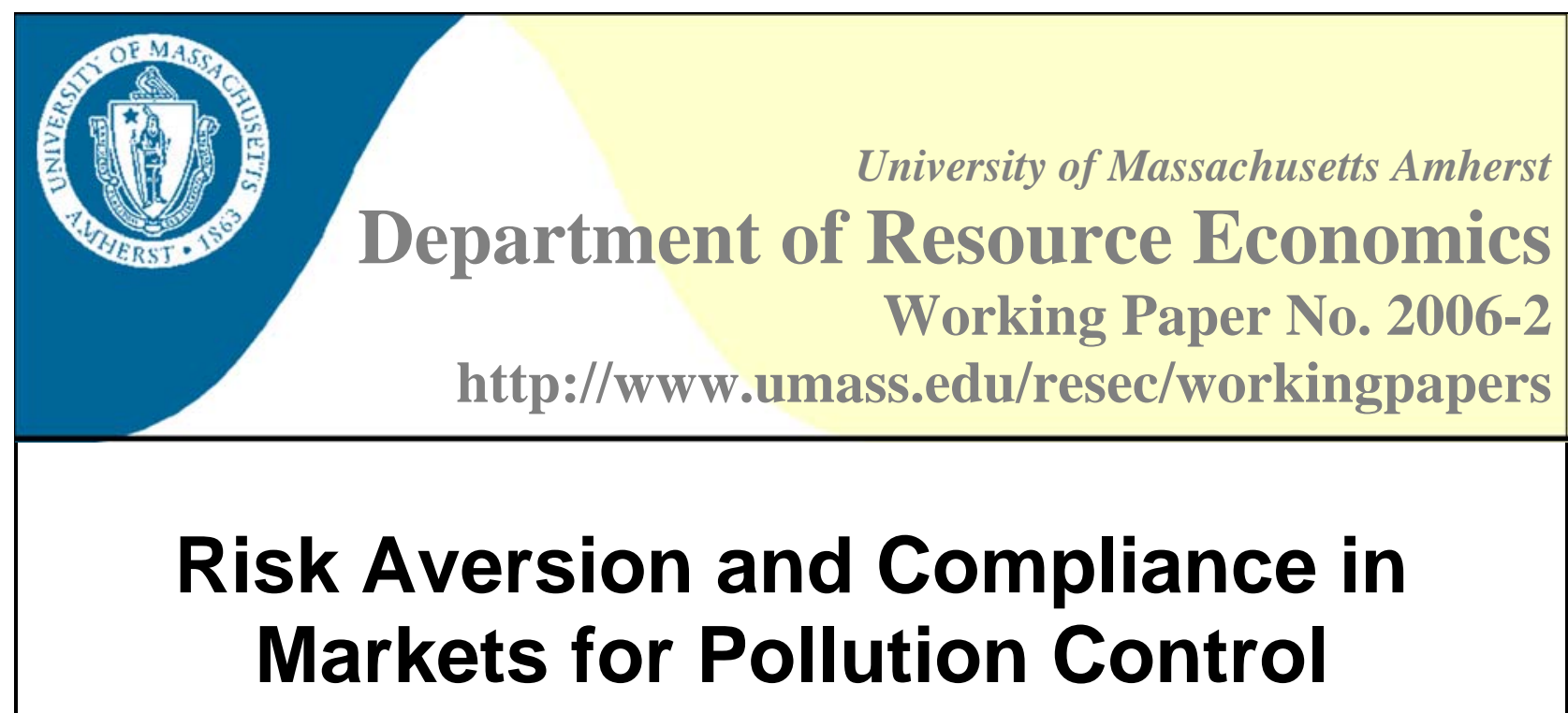

John K. Stranlund ${ }^{1}$

\begin{abstract}
:
This paper examines the effects of risk aversion on compliance choices in markets for pollution control. A firm's decision to be compliant or not is independent of its manager's risk preference. However, noncompliant firms with risk averse managers will have lower violations than otherwise identical firms with risk neutral managers. The violations of noncompliant firms with risk averse managers are independent of differences in their benefits from emissions and their initial allocations of permits if and only if their managers' utility functions exhibit constant absolute risk aversion. However, firm-level characteristics do impact violation choices when managers have coefficients of absolute risk aversion that are increasing or decreasing in profit levels. Finally, in the equilibrium of a market for emissions rights with widespread noncompliance, risk aversion is associated with higher permit prices, better environmental quality, and lower aggregate violations.
\end{abstract}

Keywords: Emissions Trading, Compliance, Enforcement, Risk Aversion

JEL Classification: L51, Q28.

\footnotetext{
${ }^{1}$ John K. Stranlund, Department of Resource Economics University of Massachusetts, 214 Stockbridge Hall, 80 Campus Center Way

Amherst, MA 01003

E: stranlund@resecon.umass.edu

P: 413-545-6328

F: $413-545-5853$
} 
August, 2006

\title{
Risk Aversion and Compliance in Markets for Pollution Control
}

\author{
JOHN K. STRANLUND \\ Department of Resource Economics \\ University of Massachusetts-Amherst
}

Correspondence to: John K. Stranlund

Department of Resource Economics

214 Stockbridge Hall

80 Campus Center Way

University of Massachusetts-Amherst

Amherst, MA 01003, USA.

Phone: (413)545-6328

Fax: (413)545-5853

E-mail: stranlund@resecon.umass.edu.

\section{Acknowledgements}

Primary funding for this research was provided by the U.S. EPA - Science to Achieve Results (STAR) Program grant \#R829608. Additional support was provided by the Cooperative State Research Extension, Education Service, U. S. Department of Agriculture, Massachusetts Agricultural Experiment Station, and the Department of Resource Economics under Project No. MAS00871. 


\title{
Risk Aversion and Compliance in Markets for Pollution Control
}

\begin{abstract}
This paper examines the effects of risk aversion on compliance choices in markets for pollution control. A firm's decision to be compliant or not is independent of its manager's risk preference. However, noncompliant firms with risk averse managers will have lower violations than otherwise identical firms with risk neutral managers. The violations of noncompliant firms with risk averse managers are independent of differences in their benefits from emissions and their initial allocations of permits if and only if their managers' utility functions exhibit constant absolute risk aversion. However, firm-level characteristics do impact violation choices when managers have coefficients of absolute risk aversion that are increasing or decreasing in profit levels. Finally, in the equilibrium of a market for emissions rights with widespread noncompliance, risk aversion is associated with higher permit prices, better environmental quality, and lower aggregate violations.
\end{abstract}

Keywords: Emissions Trading, Compliance, Enforcement, Risk Aversion

\section{Introduction}

One of the most important design elements of any regulatory policy is how compliance to the policy will be enforced. Within the context of designing market-based pollution control policies, several authors have provided theoretical analyses of compliance incentives, the consequences of noncompliance, and the design of enforcement strategies (e.g., Keeler 1991, Malik 1990, 1992, and 2002, vanEgteren and Weber 1996, Stranlund and Dhanda 1999, Stranlund and Chavez 2000, Chavez and Stranlund 2003, Stranlund, Costello and Chavez 2005). Taken as a whole, this literature suggests that firms' incentives toward noncompliance under market-based regulations, as well as the design of enforcement strategies to counteract these incentives, are quite different from compliance and enforcement of other policy instruments, particularly command-andcontrol regulations.

An important question for enforcers of environmental policies is whether differences in the characteristics of firms generate different compliance choices. One may suspect that firms with different production processes, abatement technologies, or initial allocations of emissions 
rights may have different compliance incentives. If this is true, then regulators will be motivated to choose a targeted enforcement strategy, in particular targeted monitoring effort, which is conditioned on firm-level characteristics.

However, Stranlund and Dhanda (1999) have shown that the individual compliance choices of risk neutral competitive firms in emissions trading programs are independent of differences in any firm-level characteristic. Consequently, regulators have no reason to condition their enforcement effort on firm-level characteristics. Their reasoning is straightforward. Since compliance in emissions trading programs means that a firm holds enough permits to cover its emissions, a risk neutral competitive firm's marginal benefit of noncompliance is what it has to spend for permits to make sure it is compliant; that is, the prevailing permit price. A firm's compliance decision is made by comparing this permit price with the marginal expected penalty for emissions in excess of permits. Since this marginal benefit-cost comparison does not depend on anything unique to a particular firm, the compliance decision is independent of any firm characteristic.

This independence result contrasts sharply with the effects of firm-level characteristics on compliance with command-and-control standards, under which firms with higher marginal emissions control costs or that face stricter emissions standards will have a greater incentive to be noncompliant. In this way, firm-level characteristics are important determinants of compliance with fixed standards (Garvie and Keeler 1994). A recent paper by Gray and Shadbegian (2005) finds strong support for this conclusion in their analysis of compliance behavior by pulp and paper manufacturers.

The independence of firms' violation choices on their individual characteristics under market-based regulations clearly depends, at least in part, on the assumption of risk-neutrality. 
However, no one has addressed the question of whether this independence result holds with riskaverse decision makers. In the theoretical literature on compliance and enforcement of emissions trading only Malik (1990) allows for non-neutral risk preferences. However, he does not provide the qualitative impacts of firms' benefits from emissions (i.e., emissions control costs) or their initial allocations of permits on violation choices. Doing so is the primary objective of this paper. Moreover, since market-based regulations are unique in that the compliance decisions of firms are linked together through the market for property rights, it is important to understand how risk aversion affects equilibrium decisions and market outcomes.

Several new results about compliance behavior under tradable property rights policies are derived in this paper. After laying out a model of a firm's compliance decisions under a competitive emissions trading program in the next section, section 3 contains an analysis of the effects of risk aversion on compliance behavior. I first demonstrate that a firm's decision about whether to comply or not is independent of its manager's risk preference. Thus, if the enforcement objective is to achieve full compliance to an emissions trading program, the distribution of risk preferences among the managers of firms has no bearing on the strategy required to achieve this objective. Moreover, a targeted enforcement strategy with which firms with certain characteristics are monitored more closely than others is not justified.

Risk preferences do play a role in determining the violations of noncompliant firms. Not surprisingly, noncompliant firms with risk averse managers will have lower violations than otherwise identical firms with risk neutral managers. However, the violations of noncompliant firms with risk averse managers are independent of differences in their benefits from emissions and their initial allocations of permits if and only their managers' utility functions exhibit constant absolute risk aversion. On the other hand, firm-level characteristics do impact violation 
choices when managers have coefficients of absolute risk aversion that are increasing or decreasing in profit levels.

In principle, therefore, a regulator could target its enforcement effort when there is widespread noncompliance in an emissions trading program and firms’ managers are risk averse. This targeting could be based directly on differences in the risk preferences of individual managers, or indirectly on differences in the firms’ characteristics. However, a regulator must have detailed information about managers’ risk preferences, including their coefficients of absolute risk aversion. Unfortunately, it seems unlikely that a regulator could screen individual managers on the basis of their risk preferences. It also seems unlikely that a regulator could infer this information from observed behavior. Thus, while a targeted monitoring strategy may be justified when firm managers are risk averse, the information requirements for forming such a strategy are rather severe.

Finally, it is important for regulators to understand how risk preferences affect the performance of markets for pollution control. I examine the market effects of risk aversion in section 4. Risk aversion will have no impact on rights markets when all firms are compliant, but may have significant impacts when there is widespread noncompliance. In these cases, risk aversion is associated with higher permit prices, better environmental quality, and lower aggregate violations.

\section{A Model of Compliance under Emissions Trading}

The analysis of this paper is largely based on a standard model of the decisions of a firm that operates under a competitive emissions trading program. It is important to note that the model of this paper can be applied to other tradable property rights programs with minor modifications. In 
fact, recent papers by Hatcher (2005) and Chavez and Salgado (2005) are direct applications of the literature on compliance and enforcement of emissions trading to individual transferable fishing quotas (ITQs). Thus the results of this paper apply to ITQ policies, as well as to other policies that seek to limit some activity through a market for the rights to engage in the activity.

The firm's benefit from emissions is $b(q, \alpha)$, which is strictly concave in its emissions $q .{ }^{1}$ Absent an inducement to control its emissions, the amount of pollution the firm releases is the solution to $b_{q}(q, \alpha)=0$. Denote this value of $q$ as $q^{0}$, and let us limit the analysis to emissions less than $q^{0}$. For $q<q^{0}, b_{q}(q, \alpha)>0$. One can think of $b_{q}(q, \alpha)$ as the firm's marginal abatement costs, because it reveals the firm's reduction in profit from reducing its emissions by one unit. Assume that the firm's benefits from emissions are increasing in the parameter $\alpha$ so that $b_{\alpha}(q, \alpha)>0$. Parametric differences in firms' benefits from emissions are captured by differences in $\alpha$.

The firm receives $l_{0}$ permits initially and holds $l$ permits after trading in a compliance period is complete. Competitive behavior in the permit market establishes a constant price per permit $p$. Net expenditure or revenue from trading in the permit market is $p\left(l-l_{0}\right)$.

If the firm is noncompliant, its emissions exceed the number of permits it holds and the magnitude of its violation is $v=q-l>0$. If the firm is compliant, $q-l \leq 0$ and $v=0$. To check for compliance, the firm is audited with a known probability $\pi$ and is assessed a penalty $f(v)$ if it is found to be noncompliant. There is no penalty for a zero violation, but the penalty is positive, strictly increasing, and strictly convex for positive violations.

\footnotetext{
1 See Montgomery (1972) for a demonstration of the concavity of profit in emissions for firms that are price-takers in input and output markets. Since the formulation of $b(q, \alpha)$ is quite general, strict concavity can be guaranteed in many non-competitive settings as well.
} 
Suppose that the manager of the firm is risk neutral or risk averse, and therefore has a concave (perhaps weakly) utility function $u$. Given the monitoring uncertainty, the manager choose the firm's emissions, $q$, and violation, $v=q-l$, to maximize his or her expected utility of profit

$$
U(w)=(1-\pi) u\left(w^{0}\right)+\pi u\left(w^{1}\right),
$$

where

$$
w^{0}=b(q, \alpha)-p\left(q-v-l_{0}\right),
$$

and

$$
w^{1}=b(q, \alpha)-p\left(q-v-l_{0}\right)-f(v) .^{2}
$$

Assuming that the firm has positive emissions, its level of emissions is determined by the first-order condition,

$$
\partial U(w) / \partial q=\left[(1-\pi) u^{\prime}\left(w^{0}\right)+\pi u^{\prime}\left(w^{1}\right)\right]\left(b_{q}(q, \alpha)-p\right)=0,
$$

which holds if and only if $b_{q}(q, \alpha)=p$. That is, the manager chooses the firm's emissions so that the marginal benefit from increased emissions is equal to the prevailing permit price. Note that this choice depends only on the emissions benefit parameter $\alpha$ and the going permit price $p$. Therefore, let us write the firm's optimal emissions as $\bar{q}=\bar{q}(\alpha, p)$. Our results about firms' emissions choices are summarized in our first proposition:

\footnotetext{
${ }^{2}$ This description of a manager's payoff function is easily modified to analyze compliance to an emissions tax (Malik 1990). To do so, let $l$ be the firm's report of its emissions, let $p$ be the fixed unit tax on emissions, and set $l_{0}=0$ to reflect the fact that a firm is required to pay for each unit of emissions. The results of this section and the next are obtained under the assumption of a fixed permit price. (In section 4 the permit price is determined endogenously so that we can examine the market effects of risk aversion.) Therefore, all of the results of these two sections, except those involving the effects of $l_{0}$, can be directly applied to an analysis of compliance behavior under a fixed emissions tax. Recent papers that investigate compliance behavior under an emissions tax include Macho-Stadler and Perez-Castrillo (2005), and Sandmo (2002). Only Sandmo allows for risk aversion, but he does not analyze the effects of risk aversion and firm characteristics on compliance behavior, which is the main topic of this paper.
} 
Proposition 1: A firm's choice of emissions is independent of its manager's risk preference, its endowment of permits, and the enforcement strategy it faces. ${ }^{3}$

These independence results are not new. Malik (1990) appears to have been the first to derive them in the case of emissions trading. See Harford (1978) and Sandmo (2002) for similar results in the case of an emissions tax.

That a firm's choice of emissions is independent of its manager's risk preference, its initial allocation of permits, and the enforcement strategy imply that a competitive permit market will maximize an industry's aggregate benefits from emissions when aggregate emissions are held to be no more than some fixed standard. In other words, a competitive emissions trading policy will minimize an industry's aggregate costs of holding its emissions to a fixed standard. ${ }^{4}$ However, there are situations in which Proposition 1 will fail to hold, yielding an inefficient distribution of pollution rights. Obviously, the assumption of competitive permit trading is crucial. ${ }^{5}$ Furthermore, Malik (1990) has shown that if a noncompliant firm’s subjective probability of detection is $\pi_{i}\left(e_{i}, l_{i}\right)$, with $\partial \pi_{i} / \partial e_{i}+\partial \pi_{i} / \partial l_{i} \neq 0$, then it chooses its emissions so that its marginal benefit from emissions differs from the permit price. If this is the case, then it is

\footnotetext{
${ }^{3}$ This last independence results does not imply that equilibrium levels of emissions are independent of the enforcement strategy. Enforcement will have an indirect effect on equilibrium emissions through the permit price. However, given a permit price, each firms' choice of emissions are independent of the enforcement strategy it faces. Murphy and Stranlund (2006) use laboratory experiments of emissions trading when subjects can be noncompliant to confirm the zero direct effect of enforcement on emissions, and a negative indirect effect through the impact of enforcement on permit prices.

${ }^{4}$ This has always been an important objective for analysts and policy makers alike. Montgomery's (1972) seminal work on the efficiency of competitive emissions trading takes this approach, as have many papers that have followed in the literature on emissions trading. Moreover, the ability of competitive markets to distribute emissions control responsibilities efficiently is the main justification for the widespread implementation of these markets.

${ }^{5}$ See van Egteren and Weber (1996), Malik (2002), and Chavez and Stranlund (2003) for analyses of compliance behavior under emissions trading programs in the presence of market power.
} 
unlikely that aggregate benefits from emissions will be maximized. In this paper the detection probability a firm faces is common knowledge between the firm and the regulator, and is independent of the firm's permit demand and choice of emissions.

We can now turn to a firm’s compliance decision, given its optimal choice of emissions. Since the condition under which the firm is compliant is an important aspect of this study, its violation choice needs to be constrained to be non-negative. The first-order condition for the violation level that maximizes [1] subject to this constraint is

$$
\partial U(w) / \partial v=(1-\pi) u^{\prime}\left(w^{0}\right) p+\pi u^{\prime}\left(w^{1}\right)\left(p-f_{v}(v)\right) \leq 0 \text {, if }<0 \text {, then } v=0 \text {. }
$$

This condition can be rewritten as:

$$
p-\pi f_{v}(v) R\left(v, \alpha, l_{0}, \pi, p\right) \leq 0 \text {, if }<0 \text {, then } v=0 \text {, }
$$

where

$$
R\left(v, \alpha, l_{0}, \pi, p\right)=u^{\prime}\left(w^{1}\right) /\left[(1-\pi) u^{\prime}\left(w^{0}\right)+\pi u^{\prime}\left(w^{1}\right)\right]=u^{\prime}\left(w^{1}\right) / U^{\prime}(w) .
$$

The implicit solution to [4] is the firm's optimal violation, which is denoted

$$
\bar{v}=\bar{v}\left(\alpha, l_{0}, \pi, p\right)
$$

The second order condition that guarantees that [4] identifies a unique optimal violation requires that $\pi f_{v}(v) R\left(v, \alpha, l_{0}, \pi, p\right)$ is strictly increasing in $v$. That is, $f_{v v} R+f_{v} R_{v}>0$. It is straightforward to demonstrate that this condition holds as long as the firm's manager is not a risk seeker. The consequences of risk seeking behavior are not examined in this paper. Note that I have written $R\left(v, \alpha, l_{0}, \pi, p\right)$ as being independent of the firm's level of emissions, $\bar{q}(\alpha, p)$. This follows from the fact that $w_{q}^{1}=w_{q}^{0}=b_{q}(\bar{q}, \alpha)-p=0$, which implies $R_{\bar{q}}=0$. $R\left(v, \alpha, l_{0}, \pi, p\right)$ is an adjustment of the marginal expected penalty, $\pi f_{v}(v)$, that accounts for the manager's attitude toward risk. If the manager is risk neutral, his or her utility function is 
linear, implying that $u^{\prime}\left(w^{1}\right)=u^{\prime}\left(w^{0}\right)$ and $R=1$. If the firm is compliant, $R=1$ as well, because $w^{0}=w^{1}$. However, if the manager is risk averse, his or her utility function is strictly concave. Therefore, if the firm is noncompliant, then $w^{0}>w^{1}$ and $u^{\prime}\left(w^{1}\right)>u^{\prime}\left(w^{0}\right)$. Since $(1-\pi) u^{\prime}\left(w^{0}\right)+\pi u^{\prime}\left(w^{1}\right)$ is a linear combination of $u^{\prime}\left(w^{1}\right)$ and $u^{\prime}\left(w^{0}\right)$, $u^{\prime}\left(w^{1}\right)>(1-\pi) u^{\prime}\left(w^{0}\right)+\pi u^{\prime}\left(w^{1}\right)$. This implies that $R>1$ for a noncompliant firm with a risk averse manager.

In the case of risk neutrality, it is straightforward to demonstrate Stranlund and Dhanda's (1999) result that the decision to comply and the choice of violation level are independent of any firm-specific characteristics. From [4] it is straightforward to establish that a firm with a risk neutral manager is compliant if and only if $p \leq \pi f_{v}(0)$; that is, a firm is compliant if and only if the permit price is not greater than marginal expected penalty of a slight violation. Note that the firm's benefits of pollution, as reflected in the parameter $\alpha$, and its initial allocation of permits, $l_{0}$, do not affect this decision rule. Therefore, a manager's decision about whether the firm should be in compliance is independent of these parameters. This independence extends to the violation level of a noncompliant firm as well. To see this, let [4] hold with equality, set $R=1$ and substitute the firm's optimal violation [6] to obtain $p-\pi f_{v}\left(\bar{v}\left(\alpha, l_{0}, \pi, p\right)\right) \equiv 0$. Differentiate this identity with respect to $\alpha$ to obtain $-\pi f_{v} \bar{v}_{\alpha}=0$, which implies $\bar{v}_{\alpha}=0$. This result indicates that firms' violations are independent of parametric differences in their benefits from emissions when their managers are risk neutral. The same is true for differences in firms' initial permit allocations.

Therefore, as long as managers are risk neutral, there is no reason for regulators to believe that some firms will be more likely to be noncompliant, or tend toward higher violations, 
even though they may have very different benefits from emissions or initial permit allocations. Moreover, there is no reason to believe that the marginal productivity of increased enforcement in reducing violations will differ among firms. Hence, a regulator that is motivated to target its enforcement resources to reduce incidences of noncompliance cannot do so on the basis of firmlevel characteristics when managers are risk neutral. In the next section I examine whether this result continues to hold when managers are risk averse.

\section{Risk Aversion and Compliance Behavior}

In this section let us analyze the compliance behavior of firms when their managers are risk averse. We begin with a firm's decision to be compliant or not. Perhaps surprisingly, a manager's risk preference has no bearing on whether his or her firm will be compliant. That is, regardless of the manager's attitude toward risk, the firm is compliant if and only if $p \leq \pi f_{v}(0)$.

To prove the "only if" part of this assertion, first note that if $v=0$, then $w^{0}=w^{1}$ and $R=1$. From [4], then, it is clear that $v=0$ requires $p \leq \pi f_{v}(0)$. To prove that $v=0$ if $p \leq \pi f_{v}(0)$, recall that the second order condition for the determination of $v$ requires that $\pi f_{v}(v) R$ is strictly increasing in $v$. This and $R=1$ when $v=0$ imply $\pi f_{v}(v) R>\pi f_{v}(0)$ for $v>0$. In turn, if $p \leq \pi f_{v}(0)$, then $p-\pi f_{v}(v) R<0$ for $v>0$. From [4], however, $p-\pi f_{v}(v) R<0$ for $v>0$ implies that the optimal choice of violation is $v=0$. Therefore, we conclude that $v=0$ if $p \leq \pi f_{v}(0)$.

Since a manager's decision about whether his or her firm should comply depends only on the prevailing permit price and the enforcement strategy, we have the following proposition: 
Proposition 2: A firm is compliant if and only if $p \leq \pi f_{v}(0)$. Therefore, whether a firm is compliant or not is independent of its benefits from emissions, its endowment of permits, and its manager’s risk preference.

Proposition 2 implies that firms with risk averse managers are not more (or less) likely to be compliant than firms with risk neutral managers. This result has important implications. Suppose that a regulator's objective is to use its enforcement strategy to induce full compliance to an emissions trading policy. One may suspect that it would be easier to induce full compliance by firms with risk averse managers than to induce compliance by firms with risk neutral managers, but this is clearly not the case. That a firm's decision to comply or not is also independent of its benefit from emissions and its initial allocation of permits implies that a regulator with the objective of inducing complete compliance should not pursue a targeted monitoring strategy. Minimizing the enforcement costs of inducing full compliance implies uniform monitoring of firms so that $p=\pi f_{v}(0)$.

While a firm with a risk averse manager is not more likely to be noncompliant than a firm with a risk neutral manager, a noncompliant firm with a risk averse manager will choose a lower violation than an otherwise identical noncompliant firm with a risk neutral manager. This follows from the fact that $R=1$ for a risk neutral manager and $R>1$ for a risk averse manager; that is, the expected marginal disutility of being penalized for a particular violation level is higher for a risk averse manager than for a risk neutral manager. In principle, with information on the risk preferences of individual managers, a regulator could target its enforcement effort based on this information. However, it seems unlikely that a regulator could categorize or screen managers on the basis of their risk preferences. 
There remains the possibility, however, that a regulator can use observable information that is correlated with firms' benefits from emissions to target its monitoring effort when firms have risk averse managers. This information may include observable characteristics of production technologies, levels of inputs and outputs, abatement equipment, or their initial allocations of permits. To determine whether it is possible for a regulator to do this, we need to determine whether a firm's violation depends on the parameter $\alpha$, or on its initial allocation of permits, $l_{0}$. Using [4] and [6], write the identity

$$
p-\pi f_{v}(\bar{v}) R\left(\bar{v}, \alpha, l_{0}, \pi, p\right) \equiv 0 .
$$

From [7] obtain $\bar{v}_{\theta}=-R_{\theta} f_{v} / S$, where $\theta \in\left(\alpha, l_{0}\right)$ and $S=f_{v v} R+f_{v} R_{v}>0$, which is required by the second order condition for determining an optimal violation. Since $f_{v}>0$, the sign of $\bar{v}_{\theta}$ is equal to the sign of $-R_{\theta}$. Using [5], one can calculate

$$
-R_{\alpha}=A b_{\alpha}\left[-u^{\prime \prime}\left(w^{1}\right) / u^{\prime}\left(w^{1}\right)+u^{\prime \prime}\left(w^{0}\right) / u^{\prime}\left(w^{0}\right)\right],
$$

and

$$
-R_{l_{0}}=A p\left[-u^{\prime \prime}\left(w^{1}\right) / u^{\prime}\left(w^{1}\right)+u^{\prime \prime}\left(w^{0}\right) / u^{\prime}\left(w^{0}\right)\right]
$$

where $A=(1-\pi) u^{\prime}\left(w^{1}\right) u^{\prime}\left(w^{0}\right) /\left[U^{\prime}(w)\right]^{2}>0$. Since $b_{\alpha}>0,-R_{\alpha}$ and $-R_{l_{0}}$ have the same sign as $-u^{\prime \prime}\left(w^{1}\right) / u^{\prime}\left(w^{1}\right)+u^{\prime \prime}\left(w^{0}\right) / u^{\prime}\left(w^{0}\right)$. Therefore, $\bar{v}_{\alpha}$ and $\bar{v}_{l_{0}}$ have the same sign as this term as well.

However, $-u^{\prime \prime}(w) / u^{\prime}(w)$ is the Arrow-Pratt coefficient of absolute risk aversion and the sign of $-u^{\prime \prime}\left(w^{1}\right) / u^{\prime}\left(w^{1}\right)+u^{\prime \prime}\left(w^{0}\right) / u^{\prime}\left(w^{0}\right)$ is simply a statement of whether the manager's utility function exhibits decreasing, constant, or increasing absolute risk aversion (Mas-Colell,et.al. 1995, pg. 193). Since from [2] and [3], $w^{0}>w^{1}$, if the manager's utility function exhibits decreasing absolute risk aversion, then $-u^{\prime \prime}\left(w^{1}\right) / u^{\prime}\left(w^{1}\right)+u^{\prime \prime}\left(w^{0}\right) / u^{\prime}\left(w^{0}\right)>0$. With constant 
absolute risk aversion this term is equal to zero, and with increasing absolute risk aversion this term is negative. Therefore, for a noncompliant firm with a risk averse manager we have the following proposition:

Proposition 3: The violation of a noncompliant firm with a risk averse manager is independent of its benefits from emissions and its endowment of permits if and only if the manager's utility function exhibits constant absolute risk aversion. If the manager's utility function exhibits decreasing (increasing) absolute risk aversion, the firm's violation is increasing (decreasing) in its benefits from emissions and its endowment of permits.

Violation levels of noncompliant firms are independent of parametric differences in their benefits from emissions and in their initial allocations of permits if the firms' managers have utility functions that exhibit constant absolute risk aversion. This is a generalization of Stranlund and Dhanda’s (1999) independence result that they obtained under the assumption of risk neutral managers. However, these results do not hold with non-constant absolute risk aversion. A firm's violation is increasing (decreasing) in its benefits from emissions and its initial allocation of permits if and only if its manager's utility exhibits decreasing (increasing) absolute risk aversion. Managers with decreasing absolute risk aversion take on more risk as their firms become more profitable. Given a choice of emissions and permit demand, a higher value of $\alpha$ or a larger initial allocation of permits both imply that a firm is more profitable. If the firm's manager has decreasing absolute risk aversion, then higher values of these parameters (higher profitability) lead the manager to take on more risk, and hence, to choose a higher violation. The opposite is 
true if the manager has increasing absolute risk aversion, because then he or she is motivated to take on less risk when the firm is more profitable.

The policy implication of Proposition 3 is that firms' violations are not independent of their benefits from emissions or initial allocations if their managers are risk averse with utility functions that exhibit non-constant absolute risk aversion. In principle, then, a regulator would be able to form a targeted monitoring strategy based on observable differences in firm's initial allocations of permits and on characteristics that determine their benefits from emissions. To do so, however, requires rather detailed information about individual managers’ risk preferences. It is important to note that it is simply not enough know, or assume, that managers are risk averse. If risk averse managers have constant absolute risk aversion, there is no justification for a targeted monitoring strategy that is based on firm-level characteristics. A targeted strategy is justified only when a regulator knows whether managers have increasing or decreasing absolute risk aversion. Unfortunately, it does not seem likely that a regulator could ever obtain this information, or infer it from observations of firm behavior. Thus, although a targeted monitoring strategy may be justified when firm managers are risk averse, the information requirements for forming such a strategy are rather severe.

\section{Market Effects of Risk Aversion}

Up to this point the analysis has been conducted under the assumption of a fixed price for emissions rights. However, any analysis of compliance behavior under tradable property rights must ultimately make the price of these rights endogenous. Perhaps the most important reason for doing so is that firms’ compliance choices are linked together by the market for property rights. This is one of the features of market-based environmental and natural resource policies 
that distinguish them from command-and-control regulations and from taxes.

Let us consider the following thought experiment. Start from a situation in which all the firms in an emissions trading program are noncompliant and all their managers are risk neutral. Then, let us replace a significant number, but not all, of the firms' managers with risk averse managers. Doing so allows us to trace out the effects of risk aversion on the equilibrium permit price, aggregate emissions, aggregate violations, as well as the violations of the firms with their new risk averse managers and the violations of those that keep their risk neutral managers.

Suppose that a fixed number of emissions permits are in circulation, and that when all the managers are risk neutral, all firms violate their permits so that aggregate emissions exceed the number of permits in circulation. Now replace a significant number of the firms' managers with risk averse individuals. Recall that risk averse managers will choose lower violations for their firms than their risk neutral counterparts. Thus, holding the permit price constant, the firms that acquire a risk averse manager will reduce their violations. In principle, these firms could reduce their violations by purchasing more permits or by reducing their emissions. However, recall that a firm's level of emissions is independent of its manager's preference for risk (Proposition 1). Therefore, holding the permit price constant, firms with risk averse managers will reduce their violations by demanding more permits, not by reducing their emissions.

Clearly the increased permit demand by the firms who now have risk averse managers will increase the equilibrium permit price. In response to this increase in the permit price, all firms will reduce their emissions. To see why, recall that a firm's choice of emissions, $\bar{q}=\bar{q}(\alpha, p)$, is determined from the first-order condition $b_{q}(q, \alpha)=p$. From this condition obtain $\bar{q}_{p}=1 / b_{q q}<0$, which implies that each firms' emissions are decreasing in the price of emissions permits. Thus, relative to a situation involving noncompliant firms with risk neutral 
managers, replacing a significant number of these managers with risk averse individuals will induce a higher equilibrium permit price and lower aggregate emissions. Of course, given a fixed supply of emissions permits, lower aggregate emissions imply lower aggregate violations. We conclude, therefore, that under market-based environmental policies with widespread noncompliance, risk aversion is associated with higher permit prices, better environmental quality, and higher aggregate compliance.

However, higher aggregate compliance does not imply lower violations by all firms. In fact, a significant number of risk averse managers will lead to higher violations by the firms with risk neutral managers. To demonstrate this, recall that equation [7] is the first-order condition for a positive violation by a firm evaluated at its optimal violation $\bar{v}\left(\alpha, l_{0}, \pi, p\right)$. Also recall that if the firm's manager is risk neutral, then $R\left(\bar{v}, \alpha, l_{0}, \pi, p\right)=1$. From $p-\pi f_{v}(\bar{v}) \equiv 0$, then, obtain $\bar{v}_{p}=1 / \pi f_{v v}>0$, which indicates that the violation of a firm with a risk neutral manager is increasing in the price of permits. Since a significant number of risk averse managers will tend to push the equilibrium permit price up because they demand more permits, their behavior will also lead the firms with risk neutral managers to increase their violations.

Our conclusions about the effects of risk aversion on transferable permit market outcomes are summarized in our final proposition.

Proposition 4: Relative to a market involving noncompliant firms with risk neutral managers, an otherwise identical market but with a significant number of risk averse managers will have (1) a higher equilibrium permit price, (2) lower emissions by all firms, (3) lower aggregate violations, but (4) higher violations by the firms with risk neutral managers. 
In contrast, risk aversion will have no impact on permit markets when all firms are compliant. That is, suppose we started from a situation involving compliant firms with risk neutral managers. Replacing some or all of the managers with risk averse managers will have no affect on equilibrium outcomes, because these new managers will also choose compliance for their firms. This follows from Proposition 2, which states that a firm's decision to be compliant is independent of the risk preference of its manager.

Therefore, the market effects of risk aversion are limited to situations involving widespread noncompliance. In these cases, risk aversion produces better environmental quality and lower aggregate violations. However, regulators need to always be aware of indirect price effects under tradable rights regulations. The lower violations of firms with risk averse managers puts upward pressure on the market price of rights, which in turn motivates firms with risk neutral managers toward higher violations.

\section{Conclusion}

We have examined the consequences of risk aversion on compliance behavior in markets for pollution control, and have obtained several new results with significant policy implications. First, a firm's decision about whether to comply or not is independent of its manager's risk preference; that is, firms with risk averse managers are not more (or less) likely to be compliant than firms with risk neutral (or even risk loving) managers. Thus, if the objective of a regulator is to enforce an emissions trading policy so that all firms that operate under the policy are fully compliant, the distribution of risk preferences among the managers of the firms has no bearing on what is required to achieve this objective. Moreover, one cannot justify a targeted 
enforcement strategy that involves monitoring firms with certain characteristics more closely than others.

However, risk preferences do play a role in determining the violation levels of noncompliant firms. While noncompliant firms with risk averse managers will have lower violations than otherwise identical firms with risk neutral managers, the effects of differences in firms' emissions benefits and their initial permit allocations on their violation choices depend critically on their managers' coefficients of absolute risk aversion. A firm's violation is independent of these characteristics if its manager's coefficient of absolute risk aversion is constant over profit levels. However, higher (lower) violations are associated with higher (lower) emissions benefits and initial permit allocations when a manager's coefficient of absolute risk aversion is decreasing (increasing) in profit levels.

In principle, a regulator could target its enforcement effort based directly on the risk preferences of individual managers, or indirectly on differences in the firms' characteristics. However, doing so requires that there is significant noncompliance to an emissions trading policy. Moreover, the regulator must have detailed information about managers' risk preferences, including whether their utility functions exhibit increasing, decreasing, or constant absolute risk aversion. Although a targeted monitoring strategy may be justified when firm managers are risk averse, the information requirements for forming such a strategy appear prohibitive.

It is important, however, for regulators to understand how risk preferences affect the performance of tradable rights regulations. We have seen that risk aversion will have no impact on markets for pollution control when all firms are compliant, but may have significant impacts when there is widespread noncompliance. In these cases, risk aversion is associated with higher permit prices, lower aggregate violations, and better environmental quality. 


\section{References}

Chavez, Carlos A. and Hugo Salgado. 2005. “Individual Transferable Quota Markets under Illegal Fishing.” Environmental and Resource Economics 31(3): 303-324.

Chavez, Carlos A. and John K. Stranlund. 2003. "Enforcing Transferable Permit Systems in the Presence of Market Power.” Environmental and Resource Economics 25 (1): 65-78.

Garvie, Devon and Andrew Keeler. 1994. "Incomplete Enforcement with Endogenous Regulatory Choice.” Journal of Public Economics 55: 141-162.

Gray, Wayne and Ronald Shadbegian. 2005. "When and Why do Firms Comply? Paper Mills in the 1980's.” Law and Policy 27(2): 238-261.

Harford, Jon. 1978. "Firm Behavior Under Imperfectly Enforceable Pollution Standards and Taxes.” Journal of Environmental Economics and Management 5(1): 26-43.

Hatcher, Aaron. 2005. Non-compliance and the Quota Price in an ITQ Fishery.” Journal of Environmental Economics and Management 49(3): 427-436.

Keeler, Andrew. 1991. "Noncompliant Firms in Transferable Discharge Permit Markets: Some Extensions.” Journal of Environmental Economics and Management 21: 180-189.

Macho-Stadler, Ines and David Perez-Castrillo. 2005. Optimal Enforcement Policy and Firm's Emissions and Compliance with Environmental Taxes. Forthcoming in Journal of Environmental Economics and Management.

Malik, Arun S. 2002. "Further Results on Permit Markets with Market Power and Cheating." Journal of Environmental Economics and Management 44(3): 371-90.

Malik, Arun S. 1992. "Enforcement Cost and the Choice of Policy Instruments for Controlling Pollution.” Economic Inquiry 30: 714-721.

Malik, Arun S. 1990. "Markets for Pollution Control when Firms are Noncompliant.” Journal of Environmental Economics and Management 18: 97-106.

Mas-Colell, Andreu; Michael D. Whinston, and Jerry R. Green. 1995. Microeconomic Theory. Oxford University Press.

Montgomery, W. David. 1972. "Markets in Licenses and Efficient Pollution Control Programs.” Journal of Economic Theory 5 (3): 395-418.

Murphy, James J. and John K. Stranlund. 2006. "Direct and Market Effects of Enforcing Emissions Trading Programs: An Experimental Analysis.” Forthcoming in the Journal of Economic Behavior and Organization. Published online May 15, 2006.

Sandmo, Agnar. 2002. "Efficient Environmental Policy with Imperfect Compliance.” Environmental and Resource Economics 23(1): 85-103.

Stranlund, John K. and Kanwalroop K. Dhanda. 1999. "Endogenous Monitoring and Enforcement of a Transferable Emissions Permit System.” Journal of Environmental Economics and Management 38(3): 267-282.

Stranlund, John K. and Carlos A. Chavez. 2000. "Effective Enforcement of a Transferable Emissions Permit System with a Self-Reporting Requirement.” Journal of Regulatory Economics 18(2): 113-131.

Stranlund, John K., Christopher Costello, and Carlos A. Chavez. 2005. "Enforcing Emissions Trading when Emissions Permits are Bankable.” Journal of Regulatory Economics 28(2): 181-204.

van Egteren, Henry and Marian Weber. 1996. "Marketable Permits, Market Power, and Cheating.” Journal of Environmental Economics and Management 30: 161-173. 